psychiatric wards. Their establishment was aided, on the one hand, by financial support from the so-called restructuring programmes and, on the other hand, by the payer's readiness to contract for such psychiatric services.

A detailed cost-effectiveness analysis revealed that in large mental hospitals beds were not fully used, too many patients were hospitalised for social reasons, and there was a liberal attitude to wards treatment duration. 0 ver the 5 years of reform, the number of excess beds has been reduced and the remaining ones have been better used. The average treatment duration has been shortened by 12 days, to 35 days.

\section{After-care}

While after-care in sheltered housing and hostels is desirable, there are insufficient funds for its general implementation. Moreover, funds for this purpose are regarded as improving quality of life, which does not constitute a priority within the tight constraint on budget limits.

Hypothecated funding

It should be noted that the $\mathrm{N}$ ational $\mathrm{H}$ ealth Fund formally allotted special resources to psychiatric care for the first time in the 2004 financial plan. This is an encouraging move and will improve the regional distribution of funds. There were also reforms in contracting principles, including prescriptive conditions for psychiatric service provision, developed by our Institute and approved by the psychiatric community in general.

\section{Further reading}

Langiewicz, W. \& Slupczynska-Kossobudzka, E. (2000) O rganization and financing of mental health care in Poland. Journal of Mental Health Policy and Economics, 3, 77-81.

\section{Contributions to}

the country profile section are welcome: please contact Shekhar Saxena (email saxenas@who.int).

\section{A 1997 survey} conducted by the National Statistical Coordination Board showed a poverty incidence of $31.8 \%$. If this rate is applied to the 2000 population census report then, for that year, over 24 million Filipinos can be considered poor and therefore likely to be at high risk in terms of health status.

\title{
The state of mental health in the Philippines
}

\author{
Udgardo Juan L. Tolentino, Jr
}

Executive Assistant, National Program for Mental Health and Substance Abuse, Department of Health, Philippines, email edtol.md@pacific.net.ph

$$
\text { Trons }
$$
he Philippines, known as the Pearl of the $O$ rient, is an archipelago of 7107 islands, bounded on the west by the South C hina Sea, on the east by the Pacific $O$ cean, on the south by the Sulu and Celebes Sea, and on the north by the Bashi Channel. The northernmost islands are about $240 \mathrm{~km}$ south of Taiwan and the southernmost islands approximately $24 \mathrm{~km}$ from Borneo. The country has a total land area of some $300000 \mathrm{~km}^{2}$. It is divided into three geographical areas: Luzon, Visayas and M indanao. It has 17 regions, 79 provinces, 115 cities, 1495 municipalities and 41956 barangays (the smallest geographic and political unit). It has over 100 ethnic groups and a myriad of foreign influences (including Malay, Chinese, Spanish and American).

The last official census (2000) put the population at 76498 735. However, the $N$ ational Statistics $O$ ffice Population Projections Unit estimated it to be 81081457 in 2003. The annual population growth rate (1995-2000) is 2.36\% (a reduction from the 1980s). The population is young: $38 \%$ are under 15 years old and only $3.5 \%$ over 65 years. Most $(83 \%)$ of the population is $\mathrm{C}$ atholic. The literacy rate is fairly high at $95.1 \%$ for males and $94.6 \%$ for females, which possibly accounts for the facility with which Filipinos find work abroad. Labour is, in fact, a prime export of the country.

More than half of the Philippine population resides in Luzon. W ithin that area, the $\mathrm{N}$ ational C apital Region (N CR) has $12.9 \%$ of the national population (9 906048 inhabitants in $61728 \mathrm{~km}^{2}$ of land). It is composed of 13 cities,
4 municipalities and 1693 barangays. Three cities in the NCR have emerged as the most populous: Q uezon City, Manila and Caloocan, which have populations of 2.17 million, 1.58 million and 1.18 million, respectively. Among the provinces, Pangasinan is the most populous, with 2.43 million, followed by Cebu, with 2.37 million and Bulacan, with 2.23 million people.

O pportunities brought about by economic development vary from region to region and this has affected internal migration. In 1980 , about $37 \%$ of the total population resided in urban areas. By 1990, the urban proportion of the population had increased to $49 \%$, with the N CR getting the bulk of this population increase. By the year 1995 , more than half of the population (54\%) lived in urban areas and this proportion increased further, to $59 \%$, by the end of 2000 .

A 1997 survey conducted by the $\mathrm{N}$ ational Statistical Coordination Board showed a poverty incidence of $31.8 \%$. If this rate is applied to the 2000 population census report, then, for that year, over 24 million Filipinos can be considered poor and therefore likely to be at high risk in terms of health status.

\section{General health care}

Health status indicators sourced from the $\mathrm{N}$ ational Statistics 0 ffice are shown in Table 1.

The available health resources are not only inadequate but also inequitably distributed. There are 548 government and 1146 private hospitals; the government 


\begin{tabular}{lcc}
\hline Health status indicator & Year 2001 & Year 2002 \\
\hline Life expectancy at birth (years) & & \\
$\quad$ Male & 66.63 & 66.93 \\
Female & 71.88 & 72.18 \\
Crude birth rate (per 1000 population) & 26.24 & 25.7 \\
Crude death rate (per 1000 population) & 5.83 & 5.80 \\
Total fertility rate (no. of children per woman) & Not available & 3.23 \\
\hline
\end{tabular}

Source: 1995 census-based national, regional and provincial projections, National Statistics Office.

health workforce comprises 2848 doctors, 4945 nurses, 16173 midwives and 14267 staff working in barangay health stations. Based on the population in 1997, the ratio of government health workers to population is as follows: 1 doctor per 9727 people, 1 dentist per 36 481, 1 nurse per 7361, and 1 midwife per 4503. This situation has been aggravated by increasing numbers of health workers gaining employment overseas. A wave of physicians, both general practitioners and specialists, have been shifting to nursing in order to cash in on the great demand for nurses in the USA, the UK and other countries. Already, many hospitals are finding difficulty in keeping experienced nurses and maintaining optimum standards of care as nurses use the hospitals merely to acquire the required minimum clinical experience before seeking employment abroad.

\section{Mental health care: \\ provision and demand}

The provision of mental health services is outlined in Table 2.

There has been no nationwide study on the prevalence of psychiatric disorders in the Philippines. H owever, the World Health $O$ rganization (2001) estimates that 1\% of the population suffers from severe psychiatric disorders or neurological conditions. In a country where disasters, both natural and manmade, are common, psychosocial problems abound, yet mental health remains a low priority for health agencies.

Some other studies on mental health are listed below.

- Baseline study conducted in a Pampanga municipality by the Department of Health ( $\mathrm{DOH})$ Division of Mental Hygiene (1964-67). The prevalence of mental disorders was estimated to be 36 per 1000 adults and children.

o WHO Collaborative Studies for Extending Mental $\mathrm{H}$ ealth $\mathrm{C}$ are in General Health Care Services. This was a seven-nation collaborative study conducted in 1980. It found that $17 \%$ of adults and $16 \%$ of children who consulted at three health centres in Manila had mental disorders. Significant also was the finding that depressive reactions in adults and adaptation reactions in children were frequent.

o University of the Philippines-Philippine General Hospital (UP-PG H) Study in Sapang Palay, Bulacan (1988-89). This found that the prevalence of schizophrenia was 12 per 1000 adults.
O Population Survey for Mental D isorders by the UPPGH Psychiatrists Foundation, Inc. (1993-94), done in collaboration with the Regional $\mathrm{H}$ ealth $\mathrm{O}$ ffice. This study covered both urban and rural settings in three provinces (lloilo, $\mathrm{N}$ egros $\mathrm{O}$ ccidental, and Antique). It estimated that the prevalence of mental disorders was $35 \%$. The three most frequent diagnoses among adults were: psychosis $(4.3 \%)$, anxiety $(14.3 \%)$ and panic disorder (5.6\%). The five most prevalent psychiatric conditions among ado lescents and children were: enuresis $(9.3 \%)$, speech and language disorders $(3.9 \%)$, learning disabilities (3.7\%), adaptation reactions $(2.4 \%)$ and neurotic disorders $(1.1 \%)$.

\section{Current realities of Philippine mental health care}

\section{Financing}

O nly $2-3 \%$ of the national budget is allocated to health care - a figure way below the World Health O rganization's recommendation for developing countries. Of the total health budget, the country spends only $0.02 \%$ on mental health. The primary sources of mental health financing, in descending order, are: taxation, out-ofpocket expenditure by the patient or family, and social insurance. Sadly, mental disorders are not covered by most health maintenance organisations, nor by the Philippine health insurance system.

Policy

The Philippines has as yet no mental health act. The $\mathrm{N}$ ational $\mathrm{H}$ ealth Policy was expressed in the $\mathrm{N}$ ational $\mathrm{O}$ bjectives for H ealth (1999-2004), which had two key objectives:

O a reduction in morbidity, mortality and disability and complications from mental disorders

Table 2. Numbers of psychiatric beds and professionals

\begin{tabular}{ll}
\hline Total psychiatric beds per 10000 population & 0.9 \\
Psychiatric beds in mental hospitals per 10000 population & 0.56 \\
Psychiatric beds in general hospitals per 10000 population & 0.3 \\
Psychiatric beds in other settings per 10000 population & 0.03 \\
Number of psychiatrists per 100000 population & 0.4 \\
Number of neurosurgeons per 100000 population & 0 \\
Number of psychiatric nurses per 100000 population & 0.4 \\
Number of neurologists per 100000 population & 0.2 \\
Number of psychologists per 100000 population & 0.9 \\
Number of social workers per 100000 population & 16 \\
\hline
\end{tabular}

Source: World Health Organization (2001). physicians, both general prac-

titioners and specialists, have been shifting to nursing in order to cash in on the great demand for nurses in the US, the UK and other countries. Already, many hospitals are finding difficulty in keeping experienced nurses and maintaining optimum standards of care as nurses use the hospitals merely to acquire the required minimum clinical experience before seeking employment abroad. 


\section{0}

Mental health

problems do not

affect 3 or 4 out of

5 persons, but one

out of one'

(Dr William

Menninger).

The rising costs of mental disorders are forcing managed care to the forefront of medical practice in the Philippines. Associated costs arise from: lost employment and productivity, the impact on the productivity and social function of families and carers, and premature death

(including

suicide). As

practised in the USA, a business ethos dictates the practice of medicine. o the promotion of mental health through less stressful lifestyles.

The vision enunciated in the $\mathrm{N}$ ational Mental Health Policy is 'better quality of life through total health care for all Filipinos'. It provides direction for 'a coherent, rational and unified response to the nation's mental health problems, concerns and efforts through the formulation and implementation of the mental health program strategy'. The goal of the Policy is to achieve 'mental health care through the development of efficient and effective structures, systems, and mechanisms that will ensure equitable, accessible, affordable, appropriate, efficient and effective delivery to all its stakeholders by qualified, competent, compassionate, and ethical mental health care professionals and service providers'.

Although the $\mathrm{N}$ ational $\mathrm{H}$ ealth Policy was written by the Department of $\mathrm{H}$ ealth, its policies, programmes and guidelines have reached only to the regional level. At the local level (provincial, city and municipal), the Department of Interior and Local Government implements only basic health services, based on available budget, the prio rities of local leaders, political will and local realities.

Drug misuse is a major area of concern. It has recently been given a boost with the enactment in 2002 of the Dangerous D rugs Act (Republic Act 9165). W ith this Act, the Department of $\mathrm{H}$ ealth has been tasked to set standards and monitor the operations of drug testing laborato ries, to set standards for the operation of drug treatment and rehabilitation centres, and to accredit physicians who evaluate and treat substance misuse.

Likewise, the Tobacco Regulation Act of 2003 (Republic Act 9211) explicitly assigned to the Department of $\mathrm{H}$ ealth the demand-reduction efforts concerning tobacco dependence and smoking cessation.

W ithin the Department of $\mathrm{H}$ ealth, the $\mathrm{N}$ ational Programme for Mental $\mathrm{H}$ ealth is being restructured as the $\mathrm{N}$ ational Programme for M ental $\mathrm{H}$ ealth and Substance Misuse, to reflect the changes imposed upon it by the newly revised drug law.

\section{Service delivery}

The D epartment of $\mathrm{H}$ ealth's current number of in-patient beds for mental disorders amounts to 5465. 0 f these beds, 77\% (4200) are in the $\mathrm{N}$ ational Centre for Mental Health (NCMH) in the NCR. The rest $(23 \%$, or 1265 beds) are distributed across the remaining regions. O nly 10 regions have psychiatric in-patient facilities. Mental health units have $25-100$ beds; these provide out- and in-patient care, consultation-liaison, and forensic services.

In response to the ill effects of long-term confinement and the advantages of community-based mental health strategies, acute psychiatric units (APU s) were developed. Ten government general hospitals were designated as pilot areas for the development of APUs, which initially provided out-patient services. The objective was to integrate mental health within general health care in these centres and to bring mental health services closest to where the need is. This was also part of the process of eventually phasing out the $\mathrm{NCMH}$ and distributing patients to psychiatric units in regional medical centres or provincial hospitals. Primary health workers were likewise trained in the identification and management of common psychiatric morbidities in order to prepare the community for the eventual closure of psychiatric institutions.

\section{Workforce}

There are currently 412 psychiatrists in the Philippines. Of these, over half (237 or 58\%) practise in the NCR. Similarly, the majority $(65 \%)$ of the $181(44 \%)$ boardcertified specialists practise in the NCR.

All 27 medical schools in the Philippines teach psychiatry in the undergraduate curriculum. There are 12 training centres accredited by the Philippine Psychiatric Association to offer residency training programmes in psychiatry. 0 f these accredited training centres, eight are in the NCR, 1 in the Cordillera Autonomous Region (Baguio), 1 in Region VI (lloilo), 1 in Region VII (Cebu) and 1 in Region XI (Davao).

\section{Challenges to overcome}

$\mathrm{N}$ ew mental disorders are emerging, including the behaviour disorders of youth and the mental health consequences of HIV. The absolute and relative numbers of mental and neurological disorders are expected to increase in the years to come. Demographic changes, changed patterns of substance misuse, and the successes of medications (leading to survival of people who would have died from chronic diseases) will contribute to the trend of increasing prevalence of mental health problems.

The rising costs of mental disorders are forcing managed care to the forefront of medical practice in the Philippines. Associated costs arise from: lost employment and productivity, the impact on the productivity and social function of families and carers, and premature death (including suicide). As practised in the USA, a business ethos dictates the practice of medicine.

Thus, there are major challenges to contend with. These include the following:

0 the increased incidence and prevalence of mental disorders

o the low priority given to mental health programmes and services

o separation of mental health from general health programmes

o neglect of the psychological needs of people living with chronic diseases

o stigma and discrimination against people with mental illness and substance misuse or dependence, and their families

o limited capacity for research into mental health and evaluation of mental health services

o coping with the effects of social factors negatively affecting mental health (e.g. poverty and the effect of minority status - children, women, ethnic groups disasters, armed conflict and terrorism)

o weakening of the informal social support given to people in need and of social cohesion in general

o poor community awareness of the nature and determinants of mental health and mental illness 
o limited coordination between the Department of Health, the Philippine Psychiatric Association, academia, and other agencies providing prevention, treatment, rehabilitation, disability support and social services, including housing, employment and welfare

o serio us shortages of professional w orkers trained in mental health

- lack of medicines and other resources o insufficient attention to demand-reduction and harmreduction strategies for alcohol and substance misuse and dependence.

\section{Sources}

Casimiro-Q uerubin, M. L. \& Castro-Rodriguez, S. (2002) Beyond the Physical. The State of the Nation's M ental Health: The Philippine Report. Melbourne: Centre for International Mental Health. World Health Organization (2001) Atlas: Country Profiles on Mental Health Resources. Geneva: WHO.

\section{Mental health senvices in Bermuda}

\section{David Price}

Consultant Adult Psychiatrist at St Brendan's Hospital, Bermuda, email David.Price@bermudahospitals.bm

ermuda comprises a group of small islands in

the Atlantic O cean, situated approximately $1000 \mathrm{~km}$ east of the USA. It is a self-governing crown dependency of the UK. It is the third richest country in the world, with average wages per head of US\$41 495 in 2000. Its economy is based on a flourishing offshore insurance industry and tourism.

\section{Psychiatric services}

Bermuda's health care comprises both private and public initiatives. Employees are required to obtain health insurance for themselves and their dependants. For those who are not insured, the government provides through the public system.

The island has two hospitals, King Edward VII Memorial Hospital, a general medical hospital, and a separate psychiatric unit, St Brendan's Hospital. The latter provides mental health care for the majority of the islanders and receives a budget of over US\$28 million per year.

\section{Human resources}

St Brendan's H ospital employs three adult and one child and adolescent psychiatrist. Each adult psychiatrist takes on the responsibility for providing one specialist area of service. The majority of staff in the hospital are Bermudian, although, given the global shortage of suitably qualified mental health staff, Bermuda recruits actively for doctors, nurses and allied staff in jurisdictions such as the UK, Canada, Australia and the USA. The cultural diversity of the staff produces an interesting mix of perspectives and ideas about health care policy.

\section{Overview of services}

Since the early 1980s, mental health policy within Bermuda has focused on making services more accessible, more community oriented and less stigmatised.
The closure of two long-stay wards in the 1980s provided the momentum for the development of community mental health teams. Teams are multi-disciplinary; individual members case manage up to 50 patients. Bermuda's small size facilitates assertive outreach.

There is a housing shortage for people with severe mental illness. The high cost of real estate due to the expansion of the business sector makes accommodation costs prohibitive for those on a low income and finding cheaper accommodation, such as at the island's Salvation Hostel, can be difficult. Many individuals with severe mental health problems live with their families, despite the high level of burden this frequently places on carers.

There are 25 acute hospital beds, including 5 on a psychiatric intensive care unit. Shortage of beds is unusual and this reduces the pressure to discharge patients before recovery is complete. A small rehabilitation unit offers a comprehensive package of psychosocial interventions for patients with complex needs; it has a philosophy of engagement for up to 2 years.

Two learning disability wards remain within the hospital but a government initiative aims to provide one new group home each year and a community learning disability service.

\section{Consumers of mental health services}

The population of Bermuda is some 65000 , approximately $60 \%$ Black and $40 \%$ W hite. The population is relatively wealthy and well educated.

Despite the turnover of expatriates employed in the business sector, the population is relatively static and this allows for an accurate and up-to-date case register of clients who use the service.

\section{Education and research}

St Brendan's H ospital is currently accredited for training by the Royal College of Psychiatrists. This is important to
Shortage of beds is unusual and this reduces the pressure to discharge patients before recovery is complete. A small rehabilitation unit offers a comprehensive package of psychosocial interventions for patients with complex needs; it has a philosophy of engagement for up to 2 years. 